\title{
POPULAARIKULTTUURIN POLIITTISUUS PROPAGANDASTA IDEOLOGISUUTEEN
}

Edelleenkin on mahdollista törmätä väitteeseen, jonka mukaan elokuvat ja muu populaarikulttuuri ovat vain viihdettä, ilman sen suurempaa tavoitetta vaikuttaa katsojiinsa tai maailmaan. Kuitenkin elokuvan potentiaali esimerkiksi propagandan levittämisessä tunnistettiin eri maiden poliittisessa johdossa ja liikkeissä heti esitysmuodon alkumetreillä. Tästä huolimatta 1900-luvun alkupuolella muun muassa Hollywood määritteli itsensä "harmittomaksi viihteeksi". Väite selittyy historiallisella kontekstilla, jossa elokuvien sisällön säätelyyn kohdistui sosiaalista painetta ihmisten ollessa huolissaan elokuvien moraalisesta sisällöstä, erityisesti seksistä, väkivallasta ja rikoksista, ei niinkään poliittisesta sisällöstä (ks. Balio 1995; Smith 1999). Elokuvilla, kuten muillakin populaarikulttuurin kertomuksilla, on aina ollut merkittävä rooli poliittisten tavoitteiden ja ideologioiden välittämisessä ja keskusteluiden luomisessa.

Populaarikulttuurin ja politiikan suhde on tunnustettu erityisesti propagandan kohdalla. Propaganda voidaan määritellä systemaattiseksi laajan yleisön manipuloinniksi, jolla pyritään tukemaan tiettyä (poliittista) näkökulmaa tai asiaa. Usein termiin sisältyy oletus harhaanjohtavasta ja virheellisestä tiedonvälityksestä, mikä lisää termin negatiivisia mielleyhtymiä. (Huckin 2016.) Populaarikulttuurin kohdalla propaganda ei ole selkeästi tunnistettava tai sisältöön päälle liimattu elementti, vaan se on sulautettu osaksi kertomuksia ja niiden luomia maailmankuvia. Muun muassa elokuvien kohdalla on tutkittu erityisesti maailmansotien aikaa, jolloin muun muassa Yhdysvallat, Britannia ja Saksa tekivät tiivistä yhteistyötä elokuvantekijöidensä kanssa kohottaakseen taistelutahtoa ja rakentaakseen viholliskuvia katsojiin tunteellisella tasolla vetoavien fiktiivisten tarinoiden kautta (ks. Donald 2017; Fox 2007).

Tästä huolestuneena toisen maailmansodan jälkeen psykoanalyyttinen elokuvateoriaperinne, joka pohjautui erityisesti Jacques Lacanin, Karl Marxin ja Louis Althusserin teorioihin, keskittyi kriittisesti pohtimaan, millä tavoin elokuvat ovat pakostakin vallitsevan ideologian uhreja ja miten elokuvat puolestaan uudelleen tuottavat katsojilleen hegemonista maailmankuvaa osallistuen siten johtavan luokan tai valtion ideologiseen projektiin (Murphy 2005). Yhtenä keskeisenä propagandan/ideologian välineenä he näkivät elokuvan tavan asemoida katsoja siten, että katsomiskokemuksensa aikana 
katsoja sisäistää hänelle tarjottuja näkökulmia. Alex Edelstein on nimittänyt tämänkaltaista näkemystä propagandan ja populaarikulttuurin suhteesta "vanhaksi propagandaksi", jossa tuottajat rakentavat propagandaa osaksi laajoille yleisöille suunnattuja populaarikulttuurisia tuotteita, kuten elokuvia, televisio-ohjelmia tai musiikkia. Tässä hyödynnetään kerronnallisia tekniikoita, kuten konfliktien luontia, ei-toivottujen elementtien demonisointia tai väheksymistä, toivottujen tapojen tai ratkaisujen ylistämistä ja mukaan ottamisen ja ulkopuolelle jättämisen tekniikoita. (Edelstein 2013.)

Propaganda ei kuitenkaan ole tarkoittanut aina sisältöjen muokkaamista toivotuksi, vaan yhtä lailla siihen on sisältynyt ei-toivottujen elementtien poistamista. Esimerkiksi Suomessa elokuvan yhteyttä propagandaan on edustanut Valtion elokuvatarkastamon toiminta, jossa sen perustamisesta vuodesta 1946 aina 1980-luvulle asti elokuvien jakelua säädeltiin ja sisältöä sensuroitiin paitsi moraalisten myös ulkopoliittisten syiden takia (Sedergren 2006). Propaganda ei myöskään nivoudu automaattisesti valtion tai auktoriteettitahojen toimintaan, vaan sitä ovat tehneet eri tahot omista syistään. Esimerkiksi kirjailija Kurt Vonnegut muisteli, että Vietnamin sodan aikana taiteilijoilla oli yleisenä käytäntönä vastustaa sotaa sekä julkisen keskustelun että töidensä kautta (Hoppe 2003). Propagandan moninaisuuteen viittaa myös Edelsteinin käsite "uusi propaganda", jolla hän tarkoittaa tapoja, joilla kukin voi luoda ja kuluttaa propagandaa osana populaarikulttuuria. Ilmiötä on vahvistanut sosiaalinen media ja käyttäjälähtöinen kulttuuri, ja sille on tyypillistä verkostoituminen, sisällön jakaminen, osallistavuus ja yhteenkuulumisen mainostaminen. (Edelstein 2013.) Tämä on tehnyt propagandasta myös entistä vaikeammin tunnistettavaa, sillä muun muassa meemeillä tehtävää mielipidevaikuttamista ei välttämättä pidetä niinkään propagandana kuin yhteiskunnallisena osallistumisena, ikään kuin ne voisivat toimia edelleen "harmittoman viihteen" viitekehyksessä (ks. Ahlgrenin artikkeli tässä numerossa).

On merkittävää, että puhuttaessa populaarikulttuurin poliittisuudesta huomioidaan muitakin julkisen keskustelun muotoja kuin propaganda, jonka rajat ovat väistämättä häilyviä ja muuttuvia. Silloinkin kun populaarikulttuuri ei sisällä tietoisia propagandataipumuksia, se sisältää oletuksia ihmisyydestä, yhteiskunnasta ja maailmasta, mikä tekee kaikesta populaarikulttuurista jollain tapaa poliittista tai ainakin ideologista. Populaarikulttuuri osallistuukin julkiseen keskusteluun erityisesti affektiivisuuden, kertomuksellisuuden ja viestinnällisyyden kautta. Jim McGuiganin (2005) mukaan populaarikulttuuri, joka rutiininomaisesti välittää esteettisiä ja tunteellisia näkökulmia siihen, miten elämme ja millaiseksi kuvittelemme hyvän elämän, luo affektiivisen reitin julkisuuteen ja rakentaa kuviteltuja yhteisöjä.

Luotujen maailmankuvien ideologisuuden lisäksi (ja tähän liittyen) populaarikulttuurin kohdalla on viime vuosina puhuttu erityisesti identiteettipolitiikasta, jossa identiteettikysymyksiin linkittyvät kokemuksellisuus, kulttuuri, politiikka ja valta-asetelmat. Identiteettipolitiikassa kiinnitetään huomiota yhteiskunnalliseen keskusteluun tasa-arvosta ja erityisesti seksuaalisuuteen, sukupuoleen ja rotuun liittyvään politisointiin ja julkisiin määrittelyihin (ks. esim. Fukuyama 2018). Tavat, joilla populaarikulttuurissa esitetään, uudelleen tuotetaan tai haastetaan erilaisia identiteettejä ja niiden intersektionaalisia kokemuksia, on nähty keskeisenä ideologisena vaikuttamisena niin hegemonian ylläpitämisen kuin sen haastamisen kannalta. Esimerkiksi viihdejätti Disney on onnistunut valjastamaan identiteettipolitiikan tehokkaasti tuotantoihinsa (Koushik \& Reed 2018). Konglomeraatin omistamat tuotantoyhtiöt kuten Marvel Studios ja Lucasfilm ovat onnistuneet reagoimaan yleisön vaatimuksiin 
moninaistamalla päähenkilökaartia muun muassa Tähtien sota- ja Black Panther -elokuvissa (2018). Vaikka elokuvat jättävät sijaa representaatioiden kritiikille, yleisvaikutelma on, että Disney edustaa edistystä yhteiskunnallisissa asioissa (Hassler-Forest 2018). Vastareaktiona tälle jotkut ovat kokeneet Hollywoodin levittävän niin kutsuttua "Social Justice Warrior"-propagandaa, vaikka kyse olisikin melko maltillisista muutoksista (Johnson 2018; ks. myös Arjoranta et al. artikkeli tässä numerossa).

Populaarikulttuurin poliittisuuteen kuuluu myös se, että kulttuurituotteiden tulkinta on aina yleisön käsissä. Vastaanottajat voivat tulkita heille esitettyjä asioita itselleen merkittävistä näkökulmista, eikä aina sillä tavalla kuin tuottajat ovat tarkoittaneet. Muun muassa Oliver Stonen Wall Street (1987) on tulkittu kritiikiksi 1980-luvulla vallinnutta materialismia ja rahanpalvontaa kohtaan (Stone 2000). Tulkintaa tukevat myös Stonen itsensä ja mukana olleiden näyttelijöiden kommentit. Kuitenkin Wall Street on toiminut joillekin innoittajana lähteä luomaan uraa rahoitusalalle (Comstock 2011). Kenties Gordon Gekkon (Michael Douglas) "ahneus on hyvästä" monologi Wall Streetissä normalisoi uusliberaalia eetosta tehokkaammin kuin Ronald Reaganin ja Margaret Thatcherin puheet.

Siinä missä populaarikulttuuri sisältää erilaisia ideologisia ja poliittisia, toisinaan jopa suoran propagandistisia, kertomusmalleja ja maailmankuvia, on populaarikulttuurin ja politiikan suhde korostetusti näkyvillä tuotteissa, joissa esitetään ja kommentoidaan poliittisia puolueita, poliittisen elämän tapahtumia ja poliitikkoja. Muun muassa erilaiset satiiriset komediaohjelmat, joissa kommentoidaan päivänpolitiikkaa, ovat yksi suosittu populaarikulttuurin muoto. Näiden ohjelmien on nähty vaikuttavan positiivisesti poliittiseen osallistumiseen, lisääntyneeseen tietoon politiikasta ja poliittisesta järjestelmästä ja ne ovat kannustaneet ihmisiä omien mielipiteiden muodostamiseen. Toisaalta ohjelmista on tunnistettu myös negatiivisia vaikutuksia, sillä ne ovat lisänneet katsojien kyynisyyttä poliittisia järjestelmiä ja uutismedioita kohtaan ja lisänneet negatiivisia tulkintoja poliitikoista ja politiikasta. (Ks. esim. Baumgarten \& Morris 2006; Cao \& Brewer 2008.) Komediaohjelmat eivät suinkaan ole ainoita poliittista elämää suoraan kommentoivia populaarikulttuurisia tuotteita, vaan esimerkiksi vuodesta 2016 asti yhdysvaltalainen populaarikulttuuri on liki kyllästymiseen asti ottanut kantaa Donald Trumpin presidenttiyteen (ks. Hakolan artikkeli tässä numerossa).

Populaarikulttuurin ja politiikan yhteen kietoutuminen on niin moniulotteinen ja kiehtova aihe, että se innoitti tutkijoita pohtimaan asiaa Lähikuvassa kaksoisnumeron verran. Tuplanumero tarjoaa näkökulmia siihen, miten eri tavoin voimme tunnistaa poliittisuutta populaarikulttuurista. Numeron avaa Pekka Kolehmaisen artikkeli Disco Elysium -pelistä (2019), jossa pelilliset ratkaisut mahdollistavat eri ideologisten ajattelutapojen simuloinnin pelin sisällä. Kolehmainen argumentoi, että poliittisten ideologioiden kommentointi ja esittäminen voidaan kokemuksellistaa pelaajalle pelillisyyden ja sen luomien epäonnistumisen kokemusten kautta.

Pelimaailmasta siirrytään elokuvien pariin. Kimmo Ahonen ja Rami Mähkä lähestyvät Francis Ford Coppolan elokuvaa Ilmestyskirja. Nyt (1979) esittämällä, että elokuva rakentaa yhden Vietnamin sodan historiatulkinnan, joka on omalta osaltaan toiminut välineenä menneisyyden ymmärtämiseen ja hallintaan.

Laura Seppälä jatkaa sotaelokuvien maailmassa kotimaisen Hiljaisuuselokuvan (2011) analyysillä. Samoin kuin Ahonen ja Mähkä hän argumentoi, että elokuva tuottaa kuvaa historiasta ja tällä kuvalla luodaan jaettuja kerto- 
muksia suomalaisuudesta. Seppälä käsittelee elokuvaa suhteessa uusisänmaallisuuteen, eli näkemyksiin Suomen erillissodista, joissa tuotetaan tarinoita sankaruudesta ja kansallisesta solidaarisuudesta. Seppälän teksti korostaa myös tunteiden merkitystä osana maailmankuvan rakentamista.

Tästä teemasta jatkaa Kate Moffatin artikkeli, jossa pohditaan tunteiden ja yksilöllisyyden politiikkaa Elina Hirvosen Kiehumispiste-dokumenttielokuvan (2017) kautta. Moffatin mukaan yksilöllisyys ja yksilöiden kokemukset mahdollistavat poliittisesti ja yhteiskunnallisesti tulehtuneiden aiheiden, kuten rasismin, käsittelyn. Kiehumispisteen edustama "emotiivinen" tyyli ei kuitenkaan ole kirjoittajan mukaan ongelmaton, sillä keskittyessään yksilön näkökulmaan se helposti sivuuttaa laajempien poliittisten ja taloudellisten kysymysten tarkastelun.

Monet numeroon kirjoittaneista huomioivat myös monimediaalisuuden vaikutusmahdollisuuksia. Laura Antolan artikkeli elokuvasta Spider-Man: Far from Home (2019) tuo esille, miten supersankarielokuva kuvastaa monimediaalista kulttuuria, jossa valeuutisista on tullut osa digitaalista kulttuuria. Antola näkee supersankarielokuvan tavan kommentoida totuuden jälkeistä diskurssia yhtäältä tämän aikakauden esittämisenä mutta myös sen kriittisenä kommentointina.

Supersankarielokuvat linkittyvät myös Jonne Arjorannan, Katja Kontturin, Essi Variksen ja Tanja Välisalon nörttikulttuuria valottavaan yhteisartikkeliin. Nostamalla esimerkkejä pelimaailman, sarjakuvien ja Star Wars -elokuvien parista he näkevät nörttikulttuurin ajautuneen identiteettikriisiin, jossa eri kulttuurin toimijat pyrkivät määrittelemään alakulttuuria tekemällä identiteettipolitiikkaa, mikä kohdistuu erityisesti sukupuolen kysymyksiin. Nörttikulttuurissa keskustellaankin siitä, millaisia kuulumisen ja ulossulkemisen prosesseja on hyväksyttävää tehdä populaarikulttuurissa.

Heidi Grönroos puolestaan paneutuu pohtimaan mediafandomeita ja niiden kautta tapahtuvaa julkisuuden henkilöiden fanitusta. Edellisten kirjoittajien tavoin hän nostaa esille, miten osallistuva kulttuuri mahdollistaa yhteisöllisyyden löytämisen ja alustan ilmaista omia mielenkiinnon kohteitaan. Samalla nämä alustat kuitenkin myös luovat "oikean elämän" arvoja, jotka alkavat kohdistua paitsi yhteisön jäseniin myös niihin kohteisiin, joita he fanittavat. Ihmisten toimintaan ja kokemuksellisuuteen tuntuu siten aina lomittuvan ideologisuuden ja identiteetin kysymykset.

Numeron loppupuolella jatketaan osallistuvuuden teemojen parissa osana poliittisten aiheiden kommentointia. Outi Hakolan artikkeli käsittelee, miten Donald Trumpin tapauksessa hänen esiintymisensä populaarikulttuurissa loivat pohjaa sille, millaisena (kansakunnan) johtajana äänestäjät hänet näkivät. Trump on myös innoittanut seuraajissaan osallistuvaa populaarikulttuuria, ja muun muassa sosiaalisen median meemimäisissä Trumprwave-videoissa he ovat vahvistaneet ja uudelleen luoneet Trumpin populaarikulttuurista ja populistista imagoa.

Numeron päättää Tero Ahlgrenin artikkeli vernakulaarista eli omaehtoisesta meemivideoiden tekemisestä yhtenä yhteiskunnallisen kommentoinnin muotona. Ahlgren argumentoi, että meemien avulla ihmiset voivat osallistua poliittiseen keskusteluun virallisten yhteiskunnallisten instituutioiden ulkopuolella. Hänen artikkelinsa tuo esille sitä, miten edellä mainittu "uusi propaganda" voisi toimia. Kun keskustelemme poliittisesta vaikuttamisesta populaarikulttuurin kautta, kyse ei ole enää siitä, että tietyt tuottajat lähettäisivät viestejä laajalle yleisölle, vaan kuka tahansa pystyy osallistumaan populaarikulttuurin avulla poliittiseen ja ideologiseen vaikuttamiseen. 
Toivotamme kaikille lukijoille antoisia hetkiä numeron parissa. Toivomme numeron avaavan keskustelua siitä, miten monilla eri tavoilla voimme ymmärtää populaarikulttuurin ja politiikan sekä poliittisuuden suhteita.

Helsingissä joulukuussa 2020

Outi Hakola ja Janne Salminen

\section{Lähteet}

Balio, Tino (1995) Grand Design: Hollywood as a Modern Business Enterprise, 1930-1939. History of the American Cinema, Volume 5. Berkeley \& Los Angeles: University of California Press.

Baumgartner, Jody \& Morris, Jonathan S. (2006) The Daily Show Effect: Candidate Evaluations, Efficacy, and American Youth. American Politics Research vol. 34:3, 341-365.

Cao, Xiaoxia \& Brewer, Paul (2008) Political Comedy Shows and Public Participation in Politics. International Journal of Public Opinion Research vol. 20:1, 90-99.

Comstock, Courtney (2011) Michael Douglas Is “Shocked" You Went into Investment Banking Because You Wanted to Be Gordon Gekko. Business Insider 9.2.2011. Saatavilla: <https://www. businessinsider.com/michael-douglas-is-shocked-you-went-into-investment-banking-becauseyou-admired-gordon-gekko-2011-2?r=US\&IR=T> (linkki tarkistettu 26.11.2020).

Donald, Ralph (2017) Hollywood Enlists!: Propaganda Films of World War II. London: Rowman \& Littlefield.

Edelstein, Alex (2013 [1997]) Total Propaganda: From Mass Culture to Popular Culture. New York: Routledge.

Fox, Jo (2007) Film Propaganda in Britain and Nazi Germany: World War II Cinema, Oxford: Berg.

Fukuyama, Francis (2018) Identity: Contemporary Identity Politics and the Struggle for Recognition. London: Profile Books Ltd.

Hasler-Forest, Dan (2018) 'Life Isn't Some Cartoon Musical': Neoliberal Identity Politics in Zootopia and Orange Is the New Black. Journal of Popular Culture vol. 51:2, 356-378.

Hoppe, David (2003) Vonnegut at 80. Nuvo 1.1.2003 (päivitetty 15.3.2017). Saatavilla: <https://nuvo.newsnirvana.com/news/news/vonnegut-at/article_04fdbc54-9435-54aa-992c3130443dc334.html> (linkki tarkistettu 26.11.2020).

Huckin, Thomas (2016) Propaganda Defined. Teoksessa Gae Lyn Henderson \& M. J. Braun (toim.) Propaganda and Rhetoric in Democracy: History, Theory, Analysis. Carbondale: Southern Illinois University Press, 118-136.

Johnson, Derek (2018) From the Ruins: Neomasculinity, Media Franchising, and Struggles Over Industrial Reproduction of Culture. Communication Culture and Critique vol. 11:1, 85-99. $<$ doi.org/10.1093/ccc/tcx001>

Koushik, Kailash \& Reed, Abigail (2018) Star Wars: The Last Jedi, Beauty and the Beast, and Disney's Commodification of Feminism: A Political Economic Analysis. Social Sciences vol. 7:11. <doi.org/10.3390/socsci7110237>

McGuigan, Jim (2005) The Cultural Public Sphere. European Journal of Cultural Studies vol. 8:4, 427-43. < doi.org/10.1177/1367549405057827>

Murphy, Paula (2005) Psychoanalysis and Film Theory Part 1: “A New Kind of Mirror". Kritikos: an international and interdisciplinary journal of postmodern cultural sound, text and image vol. 1. Saatavilla: <https://intertheory.org/psychoanalysis.htm> (linkki tarkistettu 3.12.2020).

Sedergren, Jari (2006) Taistelu elokuvasensuurista - Valtiollisen elokuvatarkastuksen historia 19462006. Helsinki: Suomalaisen Kirjallisuuden Seura.

Smith, Murray (1999) Theses on the philosophy of Hollywood History. Teoksessa Steve Neale \& Murray Smith (toim.) Contemporary Hollywood Cinema. London \& New York: Routledge, 3-20.

Stone, John (2000) Evil in the Early Cinema of Oliver Stone: Platoon and Wall Street as Modern Morality Plays. Journal of Popular Film and Television vol. 28:2, 80-87. <doi. org/10.1080/01956050009602826> 